\title{
Women and Girls in Hebrew High School Textbooks
}

\author{
Janan Faraj Falah ${ }^{1}$, Rana Saed ${ }^{2}$ \\ ${ }^{1}$ Arab College for Education, Haifa, Israel \\ ${ }^{2}$ Western Galilee College, Akko, Israel \\ Email:Jananf81@gmail.com, rana.saed@hotmail.com
}

How to cite this paper: Falah, J.F. and Saed, R. (2017) Women and Girls in Hebrew High School Textbooks. Open Journal of Social Sciences, 5, 251-270. https://doi.org/10.4236/jss.2017.56022

Received: April 29, 2017

Accepted: June 25, 2017

Published: June 28, 2017

Copyright (c) 2017 by authors and ScientificResearch Publishing Inc.

This work is licensed under the CreativeCommons Attribution International License (CC BY 4.0).

http://creativecommons.org/licenses/by/4.0/

\section{Open Access}

\begin{abstract}
The aim of this current study is to examine genders equality and the extent of gender stereotypes in the Hebrew Junior High school's textbooks, especially the texts of the seventh grade. This examination is based on the qualitative model, including an analysis of the 7 grade textbooks' substances. Through the process of texts analyzation, I become familiar with the extent and existence of gender stereotypes, gender roles, etc. The main findings indicate a positive change in the textbooks towards gender equality, yet it is a quite slow process, and involves many gender stereotypes which represent the weak, inferior role of women in society, such as the description of a woman as a housewife. The numbers of these stereotypes perpetuate the long standing position of man, who poses a higher, most important and dominant status. The research has found that women rights and status remain neglected and inferior; sometimes they are not mentioned in the textbooks at all. Few women were mentioned due to their position or role in society, yet the numbers are poor. Thus, there is an attempt to evoke and exercise gender equality in the Hebrew textbooks, as well as an attempt to limit and change stereotypes towards a better, equal education; however, the change is still too slow and too limited.
\end{abstract}

\section{Keywords}

Gender, Textbooks, Equality, Stereotype, Hebrew

\section{Introduction}

Teachers should be aware to hidden messages in textbooks and other study materials. The most important subjects are of language and literature which naturally contain several contents, perspectives, behaviors, values, and norms (Meller, 1991) [1]. 
Malach Pines (1996) [2] defines gender stereotypes as general, common, restrictive patterns of thinking of men and women in general, their entire personal traits and common behavior due to their biological gender, rather than examining their traits individually, each case on its merits.

The examination of gender stereotypes in the Hebrew textbooks and studies of the issue will greatly contribute to raise awareness and to improve the existing situation towards gender equality. Shahar (1999) [3] claims that the gap between the genders negatively affects women, for it leads women to lower their aspirations or gain great achievements; thus, it means a great loss to society.

As a result, women suffer from low self-esteem and lack of self-belief in their ability or skills.

Women find themselves working in inferior, poor income jobs, and a situation that characterizes most of female professions.

The main purpose of this research is to examine gender equality and the extent of gender stereotypes in the Hebrew junior high textbooks.

Studies which were made in this field in Israel have found that there is general stereotyped perception of men and women in textbooks and curricula. If educational system is considered as an upmost importance effecting element in society, it also reflects social, desirable and common values of society, as well as gender stereotypes and myths in the textbooks of all levels of learning, in early childhood, elementary school up to high school graduation, as well as in the matter of study subject (Meller, 1991) [1].

Shahar (1999) [4] emphasizes the millennium as the breakthrough of social change and gender equality. The change in relation to the subject towards both genders will eventually lead to perspectives of equality in society as a whole, from its basis-in the education system to the top of the social pyramid, in all branches. As a result, women would be able to adjust, improve and empower.

\section{Sexual Stereotypes \& Textbooks}

Sexual stereotypes and gender are considered to be an integral part the individual's daily life. Gender affects the way we conceive and view ourselves; it teaches us the normative manner of behaving.

1) The roles of gender are defined by society attitude and activity towards each gender, hence, our definition of men by culture as ambitious and competitive, leads to the expectation of being sportive and leaders, and women who are viewed as sentimental fan, are expected to back up, listen and admire their men, a passive viewer.

In order to gain gender equality, a social and cultural permission is needed, a multicultureless, particularly in encouraging cultural and social difference. Gender is defined in social-cultural aspects, the social distinction constructs and formats the concepts and presumptions towards genders. Banks (1997) [5] Specifies in his article that in order to understand a student's behavior, one must take into consideration variables of gender, class or race, which are all integrated, intersected and effect one's behavior. According to Banks [5], a gender is defined 
by well-adjusted behavior (of women and men) by the codes and norms of their society, a conduct which is predicted psychologically of them. The expectation of genders' roles varies beyond time, cultures and the micro-culture of a same society. Micro-cultures refer to special customs, values, and elements which are not generalized and are common in specific groups of culture.

The primary goal of school is to assist students acquire knowledge, skills and perception that are necessary to function well in society.

2) Stereotype is overstated in terms of categorizing all people in specific group. Many Stereotypes are accompanied by strong feelings such as love and loyalty, or hatred and fear towards the other. It is difficult to get free of these exaggerated images although they are contradicted strongly and supported by facts. Due to the fact that stereotypes establish absolutes (position) on selective collection of facts, they create an actual distortion of reality and of truth. Stereotype is a combination of prejudices. A prejudice is a strict, irrational generalization of group of people, it is a viewpoint which has set ahead, implemented generally and restrictedly while ignoring the facts, rather than taking into consideration social status, gender, sexual orientation ,age, political tendency, race or ethnicity. Prejudices can be positive or negative, and due to the fact that every culture is contaminated with prejudices, not a single person is completely freed of them, rather his/her thoughts are positive or negative (Macionis, 1999) [6].

Malach-Pines (1996) [2] defines gender stereotypes as a common, rigid, generalizing pattern of thinking in characterizing men or women, by referring them trades, feature of personality and behaviors typical to their biological sex, without examining the facts individually. Stereotypes in general and sexual stereotypes in particular are common among most people and societies. Sexual stereotypes are special and unique, for they are based on a criterion of distinction that is obvious for us all, for every one of us is defined as a man or a woman.

Each society generalizes positive and negative perceptions of both sexes, some of them are based and true and some of them are not. The most serious difficulty occurs when the perception simultaneously is negative and not based on facts.

Malach-Pines (1996)) [2] describes some aspects in which we tend to associate stereotypically attributes, roles, occupation and appearance to both sexes:

- Characteristics-independence for example appears to be masculine attribute, while tenderness as a female quality.

- Roles-the man is the provider/breadwinner in the family, while the woman is the caretaker of their children.

- Occupation-the man is a truck driver, while the woman is a receptionist or a secretary.

- Appearance-the man has wide shoulders, while a woman has small delicate hands.

According to Zifroni (1999) [7] in case of sexual stereotyping of the other sex (gender), the gender of the stereotyped group is the basis for the perception. There is consensus regarding the varied characterization (attributes, roles and practices), thus, these characteristics may attract the other gender, men or women, depending on the gender of the stereotyping and society norms. Sexual stereo- 
types result of relative differences between the sexes, who actually made out of average comparing, hence, a comparison is aimed also towards people from the same gender group, in this case, the differences are even greater than those who aimed to the other gender group.

Although our society holds an ideology of gender equality, some of the sexual stereotypes still exist, for it is hard to alter traditional entrenched perceptions, unfortunately, the ideology of equality does not always implemented.

Zifroni (1999) [7] adds that the different aspect of modernization in the Western Society has affected the family position, the definition of the genders' roles and the division of power. The effect of these aspects strikes mostly in the feminine gender group, who has gained equality to men in great aspects.

The words "masculine" and "feminine" raise associations and typical reaction, in relation to the society we live in. We encounter them on daily basis of life-in literature, textbooks, newspapers and the media. We characterize people as "masculine" or "feminine without even know them at all, for most of us share believes and preferences, positive and negative as well, which are considered a typical prominent behavior of a certain gender (Malach-Pines, 1996) [2] .

As already mentioned, Miller (1995) [8] indicates that textbooks and novels are one of the main substantial sources to socialization among the younger generation, and to the implementation of social-cultural values, whether it is written openly or carries hidden massages in the text. The textbooks' importance is by reflecting the present world, a world which contains equally both genderswomen and men, with different attributes and varied situations. In education, the feminine child/teenager aspect should be reevaluated in terms the disregarding her to lead and shape the environment, to plan her future, to work and to be independent without being a "burden". In reality, there are women working in the industry and technology, women scientists and business managers, but they still do not appear in the textbooks. Therefore, it is very important to change her image and limited characterization in work or other daily routine, and to represent her in a manner that a teenaged girl would rather aspire to become like, a role model who is able to solve problems independently without the help or support of men, who takes an active crucial role and earns her own money.

Blumberg (2007) [9] describes the extent of progress in the issue of sexual stereotypes in textbooks and curricula as a "snail-like". She specifies the varied examinations of textbooks of mathematics, science, social studies and others, especially in the junior-high and high schools in many countries, such as United States, Japan, India, Romania, Syria and India.

Most studies indicate of the varied attempts which have been made in order to remove stereotypes, and also reveal the significant changes in the style of illustrations, pictures and the use of neutral language-form, yet, in the aspects of financing and developing of positive-identity of women, the progress is less significant. Bloomberg adds that sexual stereotypes in textbooks would not vanish in the present and near future, it would occur in a "glacial pace". In addition, it should be notable that most textbooks widely ignore the positive modification in 
women's status and life over the recent years; however, there are some attempts to change this trend by forcing book shops and editors to remove and eliminate sexual blunting stereotypes from the textbooks.

There are also initiators and supporters who aim to stop and eliminate sexual stereotypes in textbooks, even though they still have not joined forces with the women organizations, which specialize in the field of prejudice and stereotypes in textbooks.

Segen \& Vaksowitz (1995) [10] and Miller (1995) [8] indicate that an analyzation of the Israeli textbooks and children and youth novels reveal that sexual stereotypes are multiple and definite, describing women in an inferior manner in relation to men, by qualities, skill and roles in society.

Segen \& Vaksowitz (1995) [10] add some findings which prove that boys and girls differ in four basic personality domains: women are described as non-intelligent, emotionally instable, passive, depressed and dependent on the group. Men on the contrary, are described as intelligent, stable, passionate, cheerful and independent.

In most of the analyzed books, women are housewives. Segen \& Vaksowitz (1995) [10] and Miller (1995) [8] have examined textbooks written in a range of 15 years and have come to the conclusion that, although public awareness of the subject has increased, reality still has not been changed much.

\section{Methodology}

\subsection{The Research Aim}

The aim of the current study is to examine the existence of sexual stereotypes and the extent of gender equality in Junior High Hebrew textbooks, especially in the seventh grade.

\subsection{Research Questions for Analyzing the Textbooks}

1) What is the frequency of appearance of men and women in the verbal part (stories, events, dilemmas) and in the part of the images (pictures, photos, illustrations) in the analyzed books?

2) Are there specific characteristics or specific roles for each gender?

3) How is the subject of gender stereotypes presented in the three textbooks?

4) Are there stereotyped remarks in the textbooks regarding both genders following the examples?

5) Does the language refer both genders?

This is the list of the seventh grade Hebrew textbooks I have chosen for my study: Eshkol, Hakerem \& IvritLaderech (Hebrew) [11].

\subsection{Research Method}

The current research is based on a qualitative research, and will include analysis of three Hebrew textbooks which are used and approved by the State Education of Israel. Each of the three textbooks carry a confirmation number, an approval 
of the Israeli Ministry of Education system, for they are based on the new curriculum, including four learning language aspects in addition to the syllabus of 2001.

There are various principles by which educators of The Ministry of Education select the textbooks, the study materials and contents of study. One of the principles in the selection of contents is to select non-biased, prejudiced, offensive or stereotyped materials. The analysis of the textbooks is done in the same manner of the contents' selection, one of the qualitative research tools which are aimed to develop awareness, understanding of concepts and to create a different description of reality. Contents' analysis includes reviewing and analysis of documents in order to maintain reliable findings and to assist obtaining knowledge and understanding of the phenomenon (Zabar Ben Yehoshua, 1990) [12].

Qualitative research also develops new possibilities for observing and understanding of the human behavior, understanding and knowledge, thus, the social academic information becomes more attractive and accessible for scholars, students and field researchers (Zabar Ben Yehoshua, 2002) [13].

In my analyzation of the textbooks, I chose sections from all chapters. In order to attain reliable accurate results, the number of sections is identical. The study presents a chapter of research findings, it includes a profound analysis of the contents' analysis of sexual stereotypes of all the chosen sections, in relation to the textbook itself and in relation to the other two (textbooks). The summary at the end of the study includes general conclusions of this analyzation of the three textbooks. The textbooks are studies among the Arabic native speakers seventh grade.

\subsection{Research Process}

The study examines the existence of sexual stereotypes in Junior High Hebrew textbooks and the extent of gender equality between men and women. The examination is done by an analysis of the content of three seventh grade textbooks which are studied in schools these days. My analyzation of contents includes the existence of sexual stereotypes, role definition, etc.

\section{Research Findings}

This chapter presents the findings based on the contents' analyzation of sexual gender stereotypes and gender equality in the three Hebrew textbooks in the seventh grade.

Following the changes in textbooks in recent years, especially in the curricula, there is a need to examine closely and profoundly the textbooks. The supervision is done by an analysis of contents in order to identify sexual stereotypes in the Hebrew textbooks, and to maintain the goal of gender equality.

All the analyzed textbooks are designed for the seventh grade and are learned in of the Arabic junior high schools, hence the conclusions.

In order to obtain reliable results, an identical number of texts were selected from all three textbooks (Table 1). 
Table 1. The title of the books and the number of selected lessons.

\begin{tabular}{cc}
\hline The title of the book & The number of the selected texts for analysis \\
\hline Eshkol & 20 \\
Hakerem & 20 \\
IvritLaderech. & 20 \\
\hline
\end{tabular}

\subsection{What Is the Frequency of Appearance of Men and Women in the Verbal Part (Stories, Events, and Dilemmas) and in the Part of the Images (Pictures, Photos, and Illustrations) in the Analyzed Books?}

The three analyzed Hebrew textbooks examine the frequency of appearance/mentioning of men and women in the verbal part of the book (stories, events, dilemmas) and in the imaging part/non-verbal (pictures, photos, illustrations). These are the findings based on the three books (Table 2).

The frequency of appearance (number of times) of men and women in the verbal part (stories, events, dilemmas) and the image part in the chapters in each textbook (Table 3).

These results clearly demonstrate the gap between the frequencies of appearance of men vs. women in the textbooks (Tables 3-5). Apparently, gender equality is not complete; women are still in inferior position and status in relation to men in many aspects, hence their smaller amount of appearance and mentioning in the textbooks.

Ariel (1995) [14] a researcher of women and men in literature, claims that prejudices against women result in negative association of feminine words, while those of masculine words are associated with neutral or even positive connotations. Thus, men are mentioned in positive or neutral contexts, while women are mentioned in negative ones. A statistic research of gender associations in words and texts proves a consistent gap and inequality, of male preference over female (Faraj Falah, 2013) [15].

It can be assumed that sexual stereotypes and gender inequality in the present day are clearly affected by the past, and are still dominant in the Hebrew textbooks.

In the past, children's literature had been focused on men-the heroes with the great adventures, both in the tale and images in the book, women, however were presented as beautiful subservient dolls, not a living creature, dolls who should observe men (the main character) from aside, to support and please them. In comparison, the present day, with the increasing recognition of authors, publishers, editors and teachers with the aspect of inequality, changes have been made, and the description of women and men has become more balanced (Faraj Falah, 2017 [16] and Blumberg, 2007 [9]). The change towards gender equality is visible, yet quiet poor and slow, as was mentioned above by Bloomberg, in describing the extent of focus on issues related to sexual stereotypes in textbooks and curricula in terms of a "Snail-like". Furthermore, men's appearance and fre- 
Table 2. Gender in the Hebrew books: the verbal part and the image part the 3 books.

\begin{tabular}{ccc}
\hline Gender & The verbal part & The image part \\
\hline Men & 1255 & 53 \\
Women & 231 & 26 \\
\hline
\end{tabular}

Table 3. Book 1-Eshkol: the verbal part and the image part ("Eshkol” textbook).

\begin{tabular}{ccc}
\hline Gender & The verbal part & The image part \\
\hline Men & 403 & 6 \\
Women & 46 & Non \\
\hline
\end{tabular}

Table 4. Book 2-Hakerem: the verbal part and the image part ("Hakerem" textbook).

\begin{tabular}{ccc}
\hline Gender & The verbal part & The image part \\
\hline Men & 591 & 26 \\
Women & 111 & 19
\end{tabular}

Table 5. Book 3-IvritLaderech: the Verbal part and the image part ("IvritLaderech" textbook).

\begin{tabular}{ccc}
\hline Gender & The verbal part & The image part \\
\hline Men & 261 & 21 \\
Women & 74 & 7 \\
\hline
\end{tabular}

quency in school textbooks prove of gender inequality, in fact, men appear twice as high than women.

In the course of analyzation of the appearance frequency of men and women in the texts, both in the verbal and image parts in the three textbooks, one text stands out in the text of the book "Hakerem"- "The Father and His Sons". It is clear already from the title of the story that the male figures-father and sons are still the dominant gender.

The story is about men and boys, women or other female figures are excluded and not mentioned at all.

The father is trying to take the role of the mother-woman and to be a mother and a father at the same time. He wants to be the only parent for his children, especially for boys who can be constantly trusted and supportive. In this manner, men become a powerful tool who eliminates the chances for gender equality in the future, conveying the younger generation massages perpetuating discrimination and oppression towards women.

\subsection{Are There Specific Characteristics or Specific Roles for Each Gender?}

By examining and analyzing of the specific characteristics of each gender and its role in these books, 189 male characters were found in higher important position and status, 4 times as higher than women. They are kings, leaders, trainers, 
coachers, security workers, actors, directors, judges, writers, lifeguards, Wazirs, princes, poets, politicians, clerks, doctors, swimmers, archaeologists, jurists, political ministers, journalists and artists, while women, only 21 in number are: teachers, school-directors, interviewers, spokeswomen, writers, queens, Princess. The rest of the female characters are of common status, most of them are mothers, young brides, and wives, at the boundaries of their home.

According to these data, the number of men with an important high role or status is almost four times higher than women (Table 6).

Therefore, it is possible to assume that there is still inequality between men and women, as it represented in the textbooks, both in the verbal and images parts. According to these results, men are still in a stronger higher status, even in the aspect of roles and positions, they retain higher and important positions than women, who are inferior and fulfill roles that are more common.

\subsection{How Is the Subject of Gender Stereotypes Presented in the Three Textbooks?}

The analysis of the three textbooks reveal that all books share common and similar elements in terms of sexual stereotypes, though differ one from each in other some elements. The analysis indicates of tendency towards equality in education, it tries to reduce the impact of sexual stereotypes on both genders, in order to provide students the trend of change, even though it is gradual and extremely slow. The textbooks still reflect gender inequality which is presented through the genders' presentation and discussion topics, the authors make an effort to implement a change, yet as stated above, it is noticeably gradual and extremely slow.

Hence, on could assume that there are specific features associated with certain gender, revealing the effect of gender stereotypes on men and women.

According to this table, women are still in almost exact stereotyped position, the women are characterized as old, housewives, forgiving, weak, common, dependent, etc. (Table 7). In the three textbooks, women's status is weaker than the status of men, they either housewives or mothers. Men constantly and explicitly remain the dominant gender; they are successful, as well as intelligent, strong, hard-working, their neither position nor status has been changed over the years.

In the first textbook of "Eshkol", the issue of gender equality is barely noticeable. This woman is presented in the same sexual depressing stereotype, in which she is inferior and even ignored in large parts of the stories. The attempt to weaken the status of men is by presenting the male character as a cheater, violent

Table 6. Gender and position.

\begin{tabular}{cc}
\hline Gender & People with high, important position or status in society \\
\hline Men & 189 \\
Women & 43 \\
\hline
\end{tabular}


Table 7. Gender roles.

\begin{tabular}{|c|c|}
\hline Women/girls & Men/boys \\
\hline Old & Rich knowledgeable \\
\hline Housewife & Helping supportive \\
\hline Forgiving & Tough distinguished \\
\hline Weak. & Saves lives modest \\
\hline Beautiful & A thief controls \\
\hline Shy & Shy educated \\
\hline Customer & Hero \\
\hline Dependent & Giant \\
\hline Wife & Mad \\
\hline Simple & Smart \\
\hline Woman & Nervous \\
\hline Mom & Violent \\
\hline Grandma & Curious \\
\hline Offering & Confident \\
\hline Confident in her decisions & Work hard \\
\hline Joyful & A leader \\
\hline Independent & A cheater \\
\hline Active & A user \\
\hline Working & Famous \\
\hline Guilty & Volunteering \\
\hline
\end{tabular}

and a thief and the female character in a higher respected position. This kind of representation alters the picture.

One of the texts "Algebra is Algebra" describes the male child assisting his mother at home-washing dishes, the kitchen floor and babysitting his little sister, and being ashamed for acting improperly.

In the second textbook "Hakerem", the change in women's status is noticeable, yet the process is still slow. In a certain text in this book, the narrator discuss with the pupils the advantages in wearing "school uniforms" and tries to convince them to agree to it, She is certain.. In another section in the book, "I, My Family and the Rest", the woman is described as confident and decisive, wisely speaking. In the text of "King Solomon \& Deborah", the queen places the king in a difficult dilemma in order to test his wisdom through her eyes. However, some texts present women in the traditional manner/stereotype: shy, beautiful and needy.

It is clear that the texts treat of women's positive qualities and gender equality very poor.

The third textbook "IvritLaderech" treats women positively and encourage gender equality, there are positive references of women, they are working, in- 
dependent, taking care of themselves and sometimes presented in important high positioned in society, happy and confident in most images (drawings). Unfortunately, there are only few texts that write and describe these qualities.

The common element of the tree textbooks is that in many of the texts, women are not mentioned at all.

\subsection{Are There Stereotyped Remarks in the Textbooks Regarding Both Genders? Following Are Examples}

In the process of analyzing, stereotyped statements in relation to both genders have been found, emphasizing the difference between the status of men and women, men are presented in a better positive and dominant manner. Yet, the change is noticeable towards gender equality, especially in the textbook of "IvritLaderech (Learning Hebrew)", still the changes is too poor and too slow.

\subsection{In the First Textbook "Eshkol"}

In relation to the gender stereotyped statements of men and women, the presented examples support the fact that men are the dominant gender in the textbook, they are much powerful and have greater roles than women. Hence, it could be concluded that gender equality is poor; women are still inferior and being ignored in relation to men in many of the texts. Some of the texts exemplify stereotyped statements, as in the story of "Wooden Spoon" in which the woman is presented as weak and she dies early in the story, this emphasizes that the woman is not important, only men are, the dominating gender, for example: "A woman got pregnant and about to give birth and dies at birth", women are not important, only men, for example: "Later on, the couple had a son", or "The father was left with his son, and took care of him devotionally...or "The grandfather is very pleased with his grandson".

The tone in the text is masculine, women are an integral part of the group which is dominated by men, and therefore, their position and status are inferior. The woman presentation in the text is secondary and her essence is merely by her gender (De Beauvoir, 2007) [17]. She gets birth and dies. Yet, the use in the word "couple" as well as in the word parents in plural "Your parents believe that..." indicate of a change towards gender equality, for they refer both genders-men and women together.

In the text "What Is True Friendship", the man is the one who supports the woman and is confident in her abilities, he teaches her to believe in herself, hugs her, listens to her, protects her and he is the source for her happiness, in this manner the man is the dominant figure, he mentally possesses her, thus, she is the weak character: "And there I found such a friend that made me realize that I'm able to make friends", "He was there for me time after time, knows how to support me in difficult times, always there ready to listen, protects me just at the right time...", "Knows exactly what I'm about to say", "He makes me smile every morning with a cup of coffee".

According to De Beauvoir (2007) [17], the woman always sees herself in a 
shadow of the other person, that is to say, man, rather than being independent and individual person. She refers to herself in comparison to her male spouse, for her, man is the meaning and justification to her existence.

In addition, it was found that throughout the text the pronouns are of male characteristics only (**in Hebrew language there are special pronouns referring men differently than women in third person), thus, there is no reference to "she" or "hers", which is clearly indicates of discrimination and inequality between women and men.

The song "Giant" focuses on the man's sense of self greatness (of the male poet): "I'm a giant, only I", "When I raise my head, stars touch my head". The man feels so tall and gigantic that he could touch the stars, thus, this is another example of characterization of the male figure as big, strong, tall and proud, entails already in the title of the song. The fact that women are not mentioned in the poem at all only intensifies gender inequality.

The song "Why Beating" stands in contrast to the one above, it refers to overt and covert violence of children and the feelings regarding this issue. The poem present the boy scared and crying. For example, "Kid you also might cry tomorrow", or "When I go to school, I sometimes cry", "He thinks he's a hero". The song is an example of the weal male, thus alters the concept of the strong powerful one which appears in many of the texts.

The text "Mathematics Is Mathematics" in the same book, exemplifies the change in gender roles, which means a change towards gender equality, in which boy is involved the family, in housekeeping and babysitting his brothers/sisters. Sentences as: "I am helping mom at home", or "Clearing the table wash the dishes", "Washing the kitchen floor", present the male figure as shy, diminishing the high powerful status we got used to.

In the text "That's How My Grandmother Speaks", there is a significant change for the benefit of women, the female figure is presented as an independent, strong, realistic, working figure, in contrary to the previous texts in the same book, sentences such as: "My grandmother is an independent woman. She goes every morning to work", or "She is a strong realistic woman" make all the difference.

\subsection{The Second Textbook of "The Hakerem"}

One of the texts "The Smart Hassan" is about a princess who falls in love with the common peasant-Hassan, the king disagrees his daughter's to marry Hassan and is seeking to "get rid" of the boy. The king finds a way to avoid the marriage but Hassan ascending his plan for he is smarter. The story is stereotyped, the princess carries features of beauty, infatuation, admire, enthusiastic and passiveness, her character is of silent bystander who does nothing and unable to get herself out of trouble, whereas the man-hero is wise, self-confident, pride and clever to find a solution. Furthermore, the male figures presented twice as high than the female ones, the princess is merely the female figure in the story. The expressions and statements also emphasize stereotypes reinforcing the power 
and dominance of the male figures, in this case, the king and Hassan overcome the princess. For example: Once upon a time there was a King, and the King had a daughter", or "The Princess is beautiful", "The King was amazed by his Wazir's wisdom and immediately sent an invitation to Hassan and the City dignitaries", "The Princess wondered about her father's change of attitude", "She was surprised to see her beloved marching proudly into the hall", "The King realized that the guy over comes him and his Wazir", "The Princess was amazed and silent admiring Hassan's wisdom".

In another text, "The Poor Is Rich", the story is about a Sheikh who wanted his daughter to marry, and she, in exchange, tells him that she won't get married unless he will find her a poor guy who is at the same time rich. Finally she got married.

The stereotyped expressions are very clear in this text, the daughter (the female figure) is described as beautiful, gentle, shy and waiting passively that her father would find her a beloved groom, as it is emphasized in the following sentences:

"Once upon a time there was a Sheikh who had a beautiful daughter, with a glowing eyes like stars, pink cheeks like roses and a an amazing voice”, or in "One day her father called her and said: You have grown and become a young lady, when would you be married so I could celebrate your wedding?", "The young lady was blushing when she was answering her father: I won't get married unless you find me a guy who is both poor and rich". The last sentence indicates of her wisdom, a positive change in the benefit of women.

The story "The Father and His Sons" emphasizes stereotyped expressions already in the title of the story. The story underlines the power of men, it is about the power of being unified: "The father gathered his sons at sunrise" or in "The older brother was working his muscles out", "If you all be reunited...nobody would be able to break you, you will be like a wall of steel".

There is no reference to women or to women's role, as if their role has been taken by the father and he became a single parent, taking both the role of the father and the mother at the same time. This story strengthens the status of men in the family even more. The text conveys a stereotypical hidden message by describing the boys following the footsteps of their fathers, it highlights and reinforces the bond between a father and his son in terms of power and dominance, they appear to be stronger and more trusted than women.

The story of "King Solomon \& Deborah" stands in comparison to the stories above, the woman's status is of a queen, she tests the man's (King Solomon) wisdom, as it emphasized in the following sentences: "She wanted to test his wisdom alone. And so did the Queen of Sheba", or "She brought the king boys and girls, every one of them was holding a nice bouquet".

Furthermore, the text of "I, My Family and Everyone Else" describes a family with issues at home, which imply of a change towards gender equality. The female narrator thinks and decides the issues and the solutions for the family, she is confident and advises: "I was thinking to replace my father and mother", "I 
also was born to a family of dad, mom, sister, brother", "When I'll grow older, I'll think what can be done to make family more pleasant", "I've looked and found: we should talk openly one with each other, out of our heart".

The story of "Because of the Honey Drop" tells the story of blood feud, in which the man is characterized in terms of murder, violence and agitation: "He held his gun, hits the grocer with the heavy wooden rifle handgrip, and killed him".

"The grocer was mad, he seized his stick and raised it to the dog's head and smashed it in a minute", "Like that? The Hunter was furious, you killed my dog? I won't shut up".

These features damage the status of men.

\subsection{The Third Textbook "IvritLaderech"}

In the story "A Conversation with the Intelligence", the talk between Lieli (the hero) and the officer emphasizes the change towards equality, there is a conversation of a man and a woman, each gender is mentioned equally for six times, yet, one cannot ignore the fact that also here the man's status or position is higher than the woman's, he is the professional who assists the female client: "Lieli: thank you, you have helped me so much!", "The Officer: you're welcomed, have a nice trip!"

In a letter that Shirin (a female figure) wrote to her friend she describes how she was spending the summer vacation, she was very happy: "I especially enjoyed the trip".

In another letter that she writes to the community center manager (also a female figure) she asks to set up a course of play and story-telling, the plot emphasizes women's prominence of high status; the manager of the community center is a woman.

The story of the "The Turtle Has Wheels" also emphasizes the important status of women, the central figure is the Safari's spokeswoman, she reports on the condition of the turtle, for example: "The Safari spokeswoman had announced last night: at first it had managed to move...".

An examination of other texts such as the story of "Hanging out at Home", reveal that the man's status and position is reduced, the man does not know what he wants: "I don't know what I want". Still, there is no reference to women in the text.

The text of "The Primrose \& the King", the King-the male figure is modest and gentle, "Every time I put the crown on my head, I remember to be gentle, humble King".

Other texts in the book emphasize the opposite, male figures are presented as strong, dominant, and in a higher status or position than women, such as the story of "I Like Whistling in the Street", although the writer is a woman, she has chosen to write about men, women are exclude. The man in the song does not care about anyone, for example, "I love to whistle. And I don't care what people might say". 
The text of "Not Only a Sports-Club" describes a joint football club for Jews and Arabs: "Recently an Arabs and Jews boys' soccer team was open in the Sharon", or "Fun-days strengthen the bond between the boys", "The boys enjoy playing together and win sports competitions". The entire text is about boys, although these days girls also play football and participate in sports-clubs. I wonder "what about girls, what would it be their contribution or response in class reading this kind of story that solely discusses boys?"

This text emphasized the existence of inequality in textbooks even today. It should be noted that this textbook had been approved in the year of 2011, that is to say, it is relatively new, thus, should have been meet the criteria of gender equality in a more accurate and equitable manner.

In addition, the text "Yohai Volunteers in the Safari", Yohai is interviewed by Shahar (2005) [4], he is presented as an enthusiastic volunteer, the question is why the book does not present a female volunteer in addition to the male-volunteer? Or why is it that in most times men are represented as active while women figures are passive or not mentioned at all?

"I was glad to go out again to this trip, and to work once again in the wildlife reservation in Africa".

In the text "Sea, Walls \& Humus", men are displayed as dominant, educated and proficient, there is no sign for women: "Daddy replied and agreed immediately", "On the way to Acre he explained little about the city's history".

Why is it a dad and not a mom?

There are quite few texts that remind famous people (men), a fact that strengthens the dominance of men and creates gender inequality, for men still control and are considered more important than women, who are still ignored or omitted from many texts, as the stories of:

1) The Great Humus;

2) La Fontaine;

3) The History of the Chocolate.

The text of the "The Great Humus", the humus was made by the "greatest male Chef of Lebanon".

In the story of "La Fontaine", "He was a poet, he was known throughout the world and was considered one of the greatest writers".

In the "History of Chocolate", in the 19th century the Dutch man had managed to make solid chocolate.

It is clear that women's position and rights are still neglected and inferior; sometimes they are not even mentioned at all. Only few minor women maintain distinguished high status in society. There is an attempt to inspire and realize gender equality, to limit and change sexual stereotypes towards a better, more equal education; however, the change is still limited.

\subsection{Does Language Refer Both Genders?}

In the first textbook "Eshkol" language is inflected in favor of men, often seems that the reference is to male only, the pronouns are in masculine form of speech 
even when it should apply both genders (also women), this is the reason why equality lacks from the this book. For example:

"Follow the sentence";

"Imagine yourself in old age, what would be your pray?";

"Copy the sentences to your notebook";

"What do you feel when your parents lecture you?".

$\left({ }^{* *} \mathrm{~A}\right.$ reminder-the Hebrew third person form, unlike the English language, distinct between female and male.)

Throughout the textbook, the use of the female form lacks, it is not shown even in brackets, or as an alternative.

The second and the third textbooks "Hakerem" and "IvritLaderech" use equally the male /female third form, by applying both genders in plural.

"We learn from the story that".

"Choose the appropriate statement in the story".

"Find the incorrect sentence".

However, in the third textbook "IvritLaderech", there is a use of an additional form, the plural one: "We Read a Letter".

\section{Discussion, Conclusions and Recommendations}

\subsection{Discussion and Conclusions}

In this work I examined the extent of gender equality, and the existence of sexual stereotypes in Hebrew textbooks in the seventh grade, by analyzing three textbooks, examining whether their substances reflect an ideology of gender equality. I found that these textbooks definitely reflect a change towards gender equality, however, the transformation is very slow, and there are still many sexual stereotypes such as describing women as housewives, emphasizing their weakness, poor, neglect and inferior status in society, sometimes at the expense of excluding them completely out of the text. The number of these stereotypes of women is greater than those of the long standing, powerful and dominant status of men. These stereotypes indicate a lack of ideology of equality.

In the course of attempting to answer the research questions, and the analyzation of the frequency of appearance of men and women in the verbal and image parts of the texts, it is clear that sexual stereotypes which are originated in the past do exist and dominant in the Hebrew textbooks in our recent times. In addition, the change towards gender equality occurs, yet, as I mentioned before, the process is too slow and too little. Blumberg [9] describes the extent of focusing on the issue related to stereotypes in textbooks and curricula in terms of "snail-like", she adds that sexual stereotypes in textbooks soon would not be ignored and would be treated meaningfully towards a change.

By examining and analyzing the unique characteristics of each gender and its roles, it is obvious that men are still in the strongest dominant position, even in terms of roles and occupation. Women find themselves inferior to men, with more common and simple roles and occupation. (Malach-Pines, 1996) [2] explains that there are some aspect in which people tend to stereotype genders by 
traits, roles, occupation and appearance. We all characterize foreign people in terms of "masculine" and "feminine", for we all transgress in stereotyping people's traits, behavior and preference in terms of our beliefs, by their prominent gender characteristics, sometimes positively and sometime negatively.

In the process of analyzation of the three textbooks, I found that there are many similarities between the books, especially in relation to presentation of sexual stereotypes. It is clear that these books support equality in education; making an effort to reduce the impact of sexual stereotypes.

According to Segen \& Vakowitz (1995) [10] and Miller (1995) [8], the analyzation of youth textbooks clearly include many sexual stereotypes, describing woman as inferior to men in terms of traits, role and skills by social definition.

It is important to note that most textbooks widely ignore the change in women's status in the recent years. However, there are attempts to change this equality by expelling and eliminating of sexual stereotypes from the textbooks.

During my analyzation, I found that stereotyped sentences or expressions create gender equality as well; men are still positively placed in a higher powerful status than woman. Both genders are described by traits and stereotyped situations. The attempt towards equality is made, especially in the textbook of "IvritLaderech", yet it is too slow and too little.

According to the current research and the analysis of the three textbooks in relation to linguistic inflection, it is clear that in the first textbook of "Eshkol", the inflection is in favor of men, often creating the impression as if it refers men only.

Therefore, equality is not noticeable in this book.

However, the second and third textbooks "Hakerem" and "IvritLaderech" apply of equally both to men and women. It is important to remember, according to the Director General of the Ministry of Education, to avoid unbalanced sexual inflection use of language. Therefore, Einat Avrahami (1989) [18] claims that female inflection in language should not be ignored in cases the text applies both genders.

Textbooks are an extremely important means, for they educate the young generation, forming their opinions and conduct later on in the future.

Textbooks contain implicit and explicit stereotypes, a media for transferring and strengthening stereotypes, placing women in traditional roles again. Thus, education and textbooks are the major agencies for perpetuating gender inequality.

In summary, the research findings indicate that although the various efforts which have been made in the field, the establishment of programs and intervention aiming to raise awareness and gender equality, the conditions are unsatisfying and the results remain practically almost the same.

Hebrew junior high textbooks indicate of a change towards sexual equality, though it is too slow. In order to improve and promote the subject of equality, effective measures should be taken, reevaluation of the textbooks, an examination of e researches beyond the mere value and extent of sexual stereotypes on 
men and women, especially the Hebrew ones. These studies should include measurement and techniques to evaluate the results in schools in general and in the entire educational system in particular.

The analysis of the Hebrew textbooks contents should be more critical and officially consistent, to measure the intensity of stereotypes. These studies will contribute greatly the next generation, for it would include more measures for a change towards gender equality. Thus, more intervention programs would be developed on wider aspects, improving minimizing sexual stereotypes and eliminating women's inferior status in a way they would be assessed more balanced and equally to men.

The reduce in sexual stereotypes which deprive women's position, would be a useful guidance towards improvement gender equality in society.

\subsection{Conclusions and Recommendations}

This research examines the extent gender equality in Hebrew textbooks in Junior High School. According to Shahar (1999) [3], consisting of gender equality in curricula textbooks by the authors of these books, serious reference to the texts, contents, the implicit and explicit messages, to fair balanced presentation of characters, would improve the self-esteem of young girls and women and allow them to identify with female role models, and on the other hand, educate men and boys to treat women equally.

The research reveals that gender stereotypes and inequality exist, and the change towards equality is too slow.

A comparison between the textbooks emphasize that although the change of thinking and awareness among authors, teachers and other educators, and although the development and establishment of principles and guidelines of writing, the approve of curricula and textbooks with proper elements of gender equality by the Ministry of Education (2001) [19] things have not been changed dramatically, the process is still too slow. These facts have been driven educators to try and improve reality, which can be done only by offering ideas, formatting of principles and laws with additional supervision and practical implementation of ideology in the Educational system and schools. Hence, it is only natural to assume that intervention programs are a necessity. The research of Einat Avrahami (1989) [18] supports this results and its findings are similar, the textbooks perpetuate traditional sexual stereotypes and thus become a means of socialization of distinct gender roles. All research findings prove that the images shown in the textbooks are extremely conservative, do not reflect reality and cause injustice to women. Contents analysis of textbooks and novels reveal the painful fact that girls and women are shown with low self-esteem, weak, passive, having guilt and other negative features. It is necessary to alter substantially the gender imagery in the textbooks, for it does not reflect society in reality. Such distorted presentation prevails students from gasping reality complexity, much more than the dichromatic manner it is presented in the textbooks. It is clear that this par- 
tial image does not allow preparation to life in the 21st century.

This should create awareness towards women's status among all politicians, educators, and authors of curricula and textbooks.

One can assume that the reasons for the sexual stereotypes and female discrimination in the Hebrew textbooks are similar to the findings Segen \& Vakowitz (1995) [10] have reached. Their analyzation of textbooks of different periods had led them to the conclusion that gender inequality in young age are reinforced later on, over the years, creating and an extensive network of images and expectations in relation to feminine and masculine.

An analysis of characteristics attributed to men and women indicate of two main reference aspects. First, "masculine" refers to winning and activating, while the other one- "the feminine" is related to motion and expression. The first refers to the external environment, while the feminine one to the interpersonal one. Hence, a balance and to fulfillment of these needs is a necessity to the development of a personality as a whole, A stereotyped education develops only one side of the personality, and ignores and suppresses the other. As a result, a personality distortion is created, meaning, women do not get social legitimation to act and being independent, men, on the other hand, are not encouraged to show emotions or show vulnerability. This is why sexual stereotypes continue and women keep being described as inferior to men by characteristics and roles.

Hebrew textbooks are considered one of the major variables and factors that could be altered towards changing, encouraging and preserving of supportive.

Environment of gender equality in school.

From this point of view, it is possible to affect positively hidden curricula, to modify and improve sexual stereotypes. In addition, with the assistance, cooperation and intervening of the Ministry of Education, these hidden texts should be tested through researches, questionnaires and interviews

Banks (1997) [6] emphasizes the need to focus on hidden curricula and texts and their implicit norms and values. Each school contains visible and hidden ones, these programs are highly important and must improve and change towards gender equality.

Shahar (1999) [3] adds additional recommendations, one of them discusses the elimination of sexual stereotypes from the images and pictures in textbooks. In 1984 the Director General of the Ministry of Education he writes "Israeli society as all modern societies, places social equality as its main goal...it also contained instructions to gender equality in school textbooks and children literature". This document actually has introduced a new policy of the Ministry towards gender equality in education.

The issue of sexual stereotypes in textbooks was and still is a major aspect in education (Faraj Falah, 2017) [16]. It is greatly discussed and examined by educators, teachers and parents. Thus, in order to enable continuous and proper equality among genders, different bodies and organizations should be take part, providing new researches and analyses, proposals and ideas for the coming future. 


\section{References}

[1] Meller, Z. (1991) A Reflections of Sexual Stereotypes the Formal State Education Textbooks in Israel. Education Journal, 13, 7-13.

[2] Malach-Pines, A. (1996) Gender Psychology-Sexual Stereotypes. In: Malach-Pines, A. and Goldberg, R., Eds., Gender Psychology, Unit 6, Open University, Tel Aviv, 131-192.

[3] Shahar, R. (1999) Equal Opportunity between Genders-Between Reality to Vision. In: Peled, A., Ed., Fifty Years to the Israeli Education, Vol. A, The Ministry of Education, Culture \& Sports, 249-268.

[4] Shahar, R. (2005) Hana'le the Little Baker, Danny the Wise Hero: The Construction of Gender in Children Popular Songs from the 20ies to 2004. Education: A Volume of the Kibbutzim Seminar, 27, 229-242.

[5] Banks, J.A. (1997) Multicultural Education: Characteristics and Goals. In: Banks, J.A. and McGee Banks, C.A., Eds., Multicultural Education: Issues and Perspectives, Allyn and Bacon, Boston.

[6] Macionis, J.J. (1999) Study Guide for Macionis Society. The Basic. Amazon.

[7] Avi, Z. (1999) Gender Stereotypes among Israeli Adolescents with Special Emphasizes on the Mail Stereotype and Its Educational Consequences. PhD Dissertation, Department of Education, Eotvos Lorand University, Bodapest.

[8] Miller, Z. (1995) A Reflection of Sexual Stereotypes (Sexists) in the Formal State Education Textbooks in Israel. In: Segen, N., Ed., Each Gender \& Its Equality, The Ministry of Education, Culture \& Sports, Jerusalem.

[9] Blumberg, R.L. (2007) Gender Bias Textbooks: A Hidden Obstacle on the Road to Gender Equality in Education, UNESCO. http://unesdoc.unesco.org/images/0015/001555/155509e.pdf

[10] Segen, N. and Vakowitz, A. (1995) Male and Female Stereotypes in Textbooks \& Children's Literature. In: Segen, N., Ed., Each Gender \& Its Equality, The Ministry of Education, Culture \& Sports, Jerusalem.

[11] Eshkol, Hakerem and IvritLaderech (Hebrew). The Education Ministry.

[12] Zabar Ben-Yehoshua, N. (1990) Qualitative Research in Teaching. Massada, Givatayim, 13-31.

[13] Zabar Ben-Yehoshua, N. (2002) The Quality Research-A Perspective for the Future. In: Shy, A. and Bar Shalom, Y., Eds., Qualitative Research in Education-From Theory to Practice and from Practice to Theory.

[14] Rubinstein, A. (1995) Correct Belief, Wrong Action and a Puzzling Gender Difference," Papers 00-17, Tel Aviv. Huberman, G. https://ideas.repec.org/e/pru8.html

[15] Faraj Falah, J. (2013) The Portrayal of Women in Israeli Arabic Textbooks on Druse Heritage. Us-China Educating Review, 3, 1.

[16] Faraj Falah, J. (2017) The Issue of Gender in Elementary Schools' Hebrew Textbooks for the Arab Sector in Israel Manuscript. British Journal of Education, BJE-413.

[17] De Beauvoir, S. (2007) The Opposite Gender. Translation: S. Preminger. Babylon, Tel Aviv.

[18] Avrahami-Einat, Y. (1989) She \& He in Class. Modan, Moshav Ben Shemen.

[19] Education (2001) Babylon, Tel Aviv, 93-102. 
Submit or recommend next manuscript to SCIRP and we will provide best service for you:

Accepting pre-submission inquiries through Email, Facebook, LinkedIn, Twitter, etc. A wide selection of journals (inclusive of 9 subjects, more than 200 journals)

Providing 24-hour high-quality service

User-friendly online submission system

Fair and swift peer-review system

Efficient typesetting and proofreading procedure

Display of the result of downloads and visits, as well as the number of cited articles Maximum dissemination of your research work

Submit your manuscript at: http://papersubmission.scirp.org/

Or contact jss@scirp.org 